\title{
General health status and morbidity pattern of bus drivers in West Bengal
}

\author{
S. Mukherjee ${ }^{1}$, C. K. Pradhan $^{2}$, I. Chakraborty ${ }^{3}$, A. Saha ${ }^{4}$, S. Thakur ${ }^{2}$, S. Sahu ${ }^{1^{*}}$ \\ ${ }^{1}$ Ergonomics and Occupational Physiology Laboratory, Department of Physiology, University of Kalyani, Nodia, 741235, West \\ Bengal, India. \\ ${ }^{2}$ Regional Occupational Health Centre (E), Block DP, Sector V, Salt Lake, Kolkata - 70009, West Bengal, India. \\ ${ }^{3}$ College of Medicine and Sagore Dutta Hospital, 578 B T Road, Kolkata- 700058, West Bengal, India. \\ ${ }^{4}$ Department of Physiology, Sister Nibedita General Degree College, Kolkata- 700 027, West Bengal, India. \\ *Corresponding Author: Subhashis Sahu, Phone No. - +919831316573(M) Email:skcsahu@yahoo.co.in
}

\section{Available online at: www.isroset.org}

Accepted: 08/Aug/2018, Online: 30/Aug/ 2018

\begin{abstract}
Bus driving is a paradigm of highly strenuous occupation, with high risks of physical and mental ill-health. The drivers must respond to various unforeseen demands over which they have petite control. In driving time they are exposed to different types of hazards but there is dearth of data. This study was aimed at evaluating the general health status of the bus drivers, their demographic profile and morbidity pattern. Bus drivers $(n=254)$ were randomly taken from different bus depot and divided into two groups according to years of experience. Different type of physical, physiological and biochemical parameters were measured. Detailed job profile of bus drivers was also analyzed with the help of questionnaire. Jaundice, skin diseases, malaria were most prevalent among the two groups of bus drivers due to unhealthy and unhygienic environmental condition at workplaces. It was also observed that most of the bus drivers of two groups had one or multiple addictions and they take it in regular basis. They were compelled to work in different types of strenuous work, which may negatively affect their work capacity along with their physiological and psychological behavior also.
\end{abstract}

Keywords: Bus drivers, health status, occupational stress, Morbidity pattern

\section{INTRODUCTION}

Bus driving is a classic example of high-strain occupation, with high risks of physical and mental occupational defenselessness, leading to absenteeism and to decreased productivity of employees and enterprises [1]. The drivers must respond to multiple unpredicted situations over which they have little control. The main tasks of a bus driver are to drive safely, and also keep on schedule. Traffic congestion is another stressor. Typically, stressful jobs are those which have high psychological demands and little decision-making control, in combination with minimum social support on the job.

Basically a general health study with the help of different physical, physiological parameters and a suitable questionnaire is much more important here to find out the occupation related problems of bus drivers. Stress is believed to play a significant role in causing certain physical (cardiovascular disease, gastrointestinal disorders, musculoskeletal problems, fatigue), psychological (depression, anxiety, post-traumatic stress disorder) and behavioral outcomes [2]. The stress factors may affect the power of coordination of the driver, causing accident. Accident can be attributed to human behavior, the environments and usually with some interaction among these. It has been also found that transport workers suffer from cardiovascular, gastrointestinal and musculoskeletal disorders [3,4,5]. It was reported that $43 \%$ bus drivers developed botulism along with gastroenteritis [6]. Professional drivers have a higher prevalence of occupational disorders than other occupational groups [7].

Age has an influence on the performance of a driver. Accident rates are highest among the young and lowest among those 40-60 years old, although visual abilities are keenest among the young and start deterioration after age of 40. It was also reported that a driver operates a bus based on the perception of visual and auditory inputs and physiological reaction [8]. The city traffic routes are mostly congested and roads are not satisfactorily maintained. The conditions become worse during seasonal extremes and undesirable climatic conditions. 
The extent of unorganized workers is significantly sky-scraping in India, but the availability of the statistical information regarding the number of people employed, health problems and other problems related to work are very poor. In unorganized transport sectors there is no proper training session for the drivers and sometimes they are recruited with inadequate experience. In India the awareness towards occupational health, safety and social security of workers are relatively deprived compared to that of the organized sectors $[9,10]$. The number of buses in unorganized sector i.e. number of privately operated bus is increasing gradually day by day.

Occupational health has not been given enough priority in India neither it is practiced frequently [11]. Most of the studies carried out by Indian investigators in the area of occupational health of bus drivers are not properly designed and quality of data is also very poor. Many times very crucial information is missed because of the reliability of research question. It is required to understand that occupational health is not a single end point incident but a consequence of events and infrequent studies can never address any issue intricately because these systems might not be single event but multiple events as a whole. The questionnaire method or the verbal protocol method of interacting with the workers, to collect information about their quality of life, health problems or other occupation related problems. Sometimes there may be disparities between the answered report and the actual situation due to various factors. So, despite its limitations observational reports were also important [12].

Considering Indian unorganized sectors as much undermined area, an attempt was made to determine the general health status, socio-economical status other morbidity pattern that are faced by the bus drivers of unorganized sector in India and this present study is intended to consider the general wellbeing parts of the bus drivers.

\section{METHODOLOGY}

\section{Subjects}

This study was proposed to evaluate the general health responses along with demographic profile and assess the morbidity pattern of the bus drivers. Subjects were included in the study after screening for acute and chronic illness. Different bus stands were visited and lists of bus drivers (age 21-60 years) were composed from privately operated buses plying in Kolkata and its surrounding areas.

Two hundred fifty four (254) drivers were randomly taken for the study from the list. All of them had minimum 3 years of work experience. According to job exposure the subject were alienated into two groups. Group 1 indicates experience less than ten years $(\exp <10)$ and Group 2 indicates exposure (experience) more than ten years (exp>10). The subjects were informed about the protocol of the study before they gave their written consent. The study was approved by ethical committee ROHC (E), Kolkata and Departmental research committee (DRC) of University of Kalyani.

\section{Physical Parameters}

The height and weight of the subjects were measured with a Martin anthropometer (Takei, Japan) and a digital weighing machine (Omran, India) respectively. Nutritional status of the subjects was assessed from their body mass index (BMI) which was calculated from body weight $(\mathrm{kg})$ and height $(\mathrm{cm})$. From anthropometric data the BMI were calculated and expressed in $\mathrm{kg} / \mathrm{m}^{2}$.

$$
\mathrm{BMI}=\text { weight }(\mathrm{kg}) / \text { height }(\mathrm{m})^{2}
$$

Body composition of the subjects in terms of body fat percentage and lean body mass were assessed from their body weight and skin fold thickness at different sites (biceps, triceps, subscapular and suprailiac) of body using skinfold calliper (Holtain, UK).

\section{Physiological Parameters}

The systolic and diastolic blood pressure was measured with an aneroid blood pressure machine at resting time of the bus drivers. Heart rate was recorded continuously using a heart rate monitor (Polar Accurex Plus, Finland).

\section{Biochemical Parameters}


Blood was drawn from the antecubital vein prior to breakfast. Blood hemoglobin percentage was determined by cyanmethaemoglobin method and plasma glucose value was estimated [13]. From the blood plasma SGPT (Serum glutamic pyruvic transaminase) and SGOT (Serum glutamic oxaloacetic transaminase) were estimated.

\section{Questionnaire study}

Based on the validated questionnaire [14], an ergonomic questionnaires were developed. The final questionnaire was redesigned and modified by several trials on the actual working condition. The question comprised details of socio-economic background, personal habit, their educational status, knowledge attitude, illness pattern and other individual or work related details. The question were prepared in English but were interviewed to the bus drivers in their local language (Bengali and Hindi) either before or after their trip.

\section{Statistical analysis}

All results were presented as mean \pm SD. Statistical comparisons among different parameters obtained in two groups of bus drivers were carried out by using a student's t test [15]. Dendogram was applied to evaluate the health problems of bus drivers.

\section{RESULT AND DISCUSSION}

From the questionnaire and interviewed the bus drivers it was came to know that bus drivers who were engaged this type of job basically migratory in nature. They came from different region from West Bengal, about $75 \%$ bus drivers were from village area for better income. As because the main intend of this study is unorganized sector, therefore we have to make out the peculiarities of privately operated bus transport system.

In unorganized bus transport system there were no any permanent salary system for bus drivers and number of trips in a day is not fixed. Total remuneration system is based commission of the per day ticket sell. If any bus driver will able to ply more trips he will get extra commission from the owner. The choice of bus driver for the bus is depend upon the desire of the owner. So bus driver wants to make more trips beyond their physical ability for extra income and satisfy the owners. It was observed from the study that early retirement of the bus drivers is very common in this unorganized sector. After the age of 50 to 55 years they couldn't continue their work due to different type of physical problems.

To find out the general health status and morbidity patterns of the bus drivers they are divided in two groups, Group 1 (experience < 10 years) and Group 2 (experience > 10 years). Basically the job of the bus drivers of these two groups is same, but bus driving is an example of high strain occupation. First of all in unorganized sector there is no any proper work schedule. Bus drivers have to start their first trip at more or less 5:00 to 5:30 am. After completing a trip of 2 to 2:30 hrs trip next they get 10 to 15 minutes for refreshment. They have no any proper lunch time and compiled to end their trip at 12:00 to 12:30 am. A bus driver must respond to multiple demands. Details of the job description are given diagrammatically in figure 2.1 .

Table 1 represents the physical parameters of the two groups of bus drivers. All the physical parameters show significant result between two groups. Mean value of BMI indicated the bus drivers as 'normal healthy' category; however, in group 1 overweight $(25 \%)$ and underweight (10\%) subjects were located and overweight $(42.1 \%)$ and underweight $(3.5 \%)$ subjects were located in group2. Their BMI and BSA value shows a significant result between two groups. It was assessed from the subject's waist hip ratio that $55.7 \%$ subjects had abdominal obesity in Group 1 and $84.2 \%$ subjects had abdominal obesity in Group 2 and shows a significant result [16]. It was also reported in earlier study that the presence of abdominal obesity in the majority of bus drivers as evidenced by waist hip ratio indicates defect in energy metabolism in this group [17].

Table 2, shows the physiological parameters of bus drivers. Heart rate, SBP, DBP, these parameters show a significant result between two groups. Although these parameters were in the normal range, but also level of exposure has play a very important role here. These all parameters were related with the age or level of exposure. According to the level of exposure the value of these parameters is also increased.

Result of the biochemical parameters were presented in table 3. From the table it was cleared that according to the age the value of hemoglobin is decreased and it is quite normal for the bus drivers. They were bare to continuous exposure of typically unhealthy environment, which may leads to an alarming situation of such physiological parameters. That is why it does not show any significant result. Same result was shown on blood glucose, from the mean value of blood glucose it was cleared that the value of glucose was in normal range. But in some other biochemical parameters like SGPT and SGOT shows 
a significant result in between two groups. This result indicated an alarming health sign of bus drivers. Basically the quality of food which they were intake regular basis, was not up to the mark or unhealthy. Not only the quality of food but also the proper timing was very much essential for a healthy life. Quality of water was another important issue here. From the questionnaire it was cleared that most of the drivers were addicted to alcohol and they take it regular basis. It would be one of the cause of that type of result. Simultaneously, this problem may be related with drivers' body weight and increase the abdominal obesity, which may associated with the musculoskeletal pain also.

Demographic profile of two groups of bus drivers were shown in table 4. Most of the bus drivers in two groups were family person (72.9\% and $92.1 \%$ of Group 1 and Group 2 respectively). From the questionnaire, it was revealed that $55.7 \%$ bus drivers from Group 1 and $44.7 \%$ from Group 2 had minimum literacy knowledge. 23.65\% bus drivers of Group 1 and 17.6\% of Group 2 had knowledge up to class X standard respectively. Most of the drivers of two groups were live in a joint family. $56.4 \%$ of Group 1 drivers were settled with 4-6 family members, where as Group 2 had 50\% of that. From the questionnaire it was revealed that according to the experience the income is gradually increased. Though the income of drivers was commission basis but there was a value of experience also.52.1\% and 29.8\% of bus drivers of Group 1 and Group 2 were earned 6,000 8,000 per month respectively. $47.4 \%$ of bus drivers of Group 2 were earned 8,000 - 10,000 per month where as 35\% of Group 1 were earned like that. Income of the bus drivers were depending on the experience of the bus drivers and number of trip they completed. Absenteeism of the drivers is very common in this private sector. After 4 to 5 days of continuous work they take 2 to 3 days of holiday. In this time they were went to their residence and engaged with some different work. $97.9 \%$ driver of Group 1 and $88.6 \%$ of Group 2 was non-vegetarian. In working days drivers get very minimum time for breakfast or lunch. Within 15 to 20 minutes interval they had to complete their bath and lunch. They ought to complete their lunch in road side hotel with very unhealthy and unhygienic condition.

Table 5 represents the personal habits of the two groups of bus drivers regarding their types of addiction. It was observed that most of the bus drivers of two groups had one or multiple addictions. In this study, it was observed that both the group $1(30 \%)$ and group $2(53.5 \%)$ were addicted to cigarette. $45.7 \%$ of Group 1 and $71.9 \%$ of Group two drivers were addicted to bidi, which were available to small packets. Both of the two groups were $(62.1 \%$ and $72.8 \%)$ addicted to chewing tobacco. It was found from the study that two groups of bus drivers were mostly addicted to bidi, chewing tobacco and ghutka and they took it at intervals, even while at work. $65.7 \%$ bus drivers of group 1 and $89.5 \%$ bus drivers of group 2 were addicted to alcohol, and they take it regular basis at the night after the finishing of their daily work.

Table 6 shows the working environmental conditions as felt by the two groups of bus drivers. Most of the drivers reported that summer was the most hectic and unwanted time for their work. $89.2 \%$ of group 1 and $90.3 \%$ drivers of group 2 were reported that hot condition is the main hindrance of their work along with humidity. In winter those problems had minimum effects of their daily work. But dusty condition of road and surrounding was the main problems of the both groups of the bus drivers. $53.6 \%$ bus drivers of group 1 and $49.1 \%$ bus drivers of group 2 were reported in winter dusty environment of surroundings made a big impact on their day to day work. The atmosphere contains various gases in different concentrations. Most of the air pollutants are hazardous to human health as well as to plants. Air pollutants such as SPM, SOx, $\mathrm{NO}_{x}$ and $\mathrm{O}_{3}$ from automobile exhaust and industries along with many other unknown pollutants are responsible for bad air quality. These pollutants affect the foliar morphology of plants also and cause deterioration of air quality [18].

General health problems of the bus drivers as seen from the medical records or from questionnaire have been represented graphically in figure 2. Health problems have been broadly classified as: Tuberculosis, jaundice, hypertension, respiratory diseases, cardiovascular diseases, skin diseases, malaria and thyroid disorders respectively.

Analysis of figure 2 showed that jaundice, skin diseases, malaria was most prevalent among the two groups of bus drivers. $41.4 \%$ and $55.3 \%$ of bus drivers of group 1 and group 2 were suffered from jaundice respectively. The main cause of that problem was insufficient and unhygienic water and food intake by the bus drivers. It was realized from the study that most of the bus drivers were spent their daily life at bus depot or in the bus also. They didn't get time for full refreshment like bath and sent their life in very unhealthy atmosphere. $48.6 \%$ and $69.3 \%$ bus drivers of group 1 and group 2 were suffered from skin diseases respectively. It was revealed from the study that $30.7 \%$ bus drivers of group 1 and $60.5 \%$ bus drivers of group 2 were suffered from malaria also. It is really an alarming situation for the bus drivers, because most of them were spent their night life in the bus or bus depot with out any protection of insects and biological agents.

In figure 3 dendrogram was applied to evaluate the health problems of bus drivers. From dendrogram we can concluded that the all the variables were clustered at the base of the dendrogram. A dendrogram is a tree diagram which is frequently used to illustrate the arrangement of the clusters produced by hierarchical clustering. In figure it shows that dendrogram has 25 scale arrangements, but in this case we considered up to 5 scale arrangement. From the figure it was clearly 
shows that in 0 level variable 5, 8, and 1 were clustered together. In level 5 variables like 5, 8, 1, 4 and 3 were clustered. From the dendrogram we could conclude that those variable which were more prone to two groups of bus drivers, because this type of diseases were highly associated with the day to day work of both group of bus drivers.

Table 7 shows the rotated component matrix of eight variables of two groups of bus drivers. From the table we could conclude that from component 1 variable 5 and 8 shows a closely association with this type of bus driving job, where as other component like component 2, 3, 4 are then associated with this particular type of job. If we considered component 1 the variables like 5 and variable 8 are highly related with the health effects of two groups of bus drivers. Dendrogram and rotated component shows the same result in this type of analysis.

Figure 4, below was the most vital part of the questionnaire, perception about the job where both the groups were asked to give a comment about their job that was performed by them regularly. From the figure 4 it was reflected the attitude of bus drivers while at work. It was very interesting to note that $10.7 \%$ of group 1 and $9.7 \%$ of group 2 bus drivers were reported that the work which they were performed regularly was light, where most of the bus drivers of both groups (45\% and $44.7 \%$ respectively) were reported as heavy. $20.7 \%$ bus drivers of group 1 and $17.5 \%$ drivers of group 2 also were reported as very heavy. There was very meaningful information that $3.6 \%$ and $7.9 \%$ bus drivers of both groups respectively were reported the bus driving job which they were performed regular basis was extremely heavy. It may be due to the exposure of continuous exposure of regular basis unhealthy, monotonous life. May be physical and mental ill health was another reason for that type of perception.

\section{CONCLUSION}

It was observed from the study that most of the bus drivers of both groups were married and they were separately lived due to their job demand. They forced to live an unhealthy environment and got very minimum time for refreshment. Most of the drivers had minimum literacy knowledge. Basically all bus drivers were recruited this unorganized sector on temporary basis. They had no any fixed salary, remuneration was commission basis. Most of the bus drivers were earned 8,000-10,000 per month. It was observed that most of the bus drivers of two groups had one or multiple addictions. It was found from the study that two groups of bus drivers were mostly addicted to beedi, chewing tobacco and ghutka and they took it at intervals, even while at work. Most of the drivers of both groups were addicted to alcohol, and they take it regular basis. It was revealed from the study that jaundice, skin diseases, malaria was most prevalent among the two groups of bus drivers due to unhealthy and unhygienic working environmental condition. They were compelled to work in different type of environmental condition, which may negatively affect their work capacity along with their physiological and psychological behavior also. Various addictions of bus drivers may evidently decrease their work capacity.

\section{ACKNOWLEDGEMENT}

Authors express their gratitude to the Director, NIOH, Ahmedabad for their guidance and support. The authors are gratified to ICMR, New Delhi and PRG and PURSE grant (University of Kalyani) for partial financial support to Dr. Subhashis Sahu, to carry out this study. Authors are also grateful to the bus drivers for their contribution and cooperation to conduct the study.

\section{Figures and Tables}

Table 1: Physical parameters of two groups of bus drivers

\begin{tabular}{|c|c|c|c|c|}
\hline \multirow{2}{*}{ Parameter } & \multicolumn{2}{|c|}{ Bus drivers } & \multirow{2}{*}{ t value } & \multirow{2}{*}{$P$ value } \\
\hline & Group $1(n=140)$ & Group $2(n=114)$ & & \\
\hline $\begin{array}{c}\text { Age } \\
\text { (years) }\end{array}$ & $\begin{array}{c}32.18 \pm 3.70 \\
(24-40)\end{array}$ & $\begin{array}{c}41.82 \pm 5.66 \\
(30-56)\end{array}$ & 16.3227 & $<0.001 *$ \\
\hline $\begin{array}{l}\text { Height } \\
\text { (in cm) }\end{array}$ & $\begin{array}{c}162.51 \pm 5.77 \\
(146-176)\end{array}$ & $\begin{array}{c}164.46 \pm 5.55 \\
(149-178)\end{array}$ & 2.7250 & $=0.0069^{*}$ \\
\hline $\begin{array}{l}\text { Weight } \\
\text { (in } \mathrm{Kg} \text { ) }\end{array}$ & $\begin{array}{c}55.20 \pm 9.99 \\
(37-82) \\
\end{array}$ & $\begin{array}{c}61.32 \pm 10.15 \\
(40-87)\end{array}$ & 4.8213 & $<0.001^{*}$ \\
\hline $\begin{array}{l}\text { BSA } \\
\left(\mathrm{m}^{2}\right)\end{array}$ & $\begin{array}{c}1.64 \pm 0.15 \\
(1-2)\end{array}$ & $\begin{array}{c}1.73 \pm 0.14 \\
(1-2)\end{array}$ & 4.8998 & $<0.001^{*}$ \\
\hline $\begin{array}{c}\text { BMI } \\
\left(\mathrm{Kg} / \mathrm{m}^{2}\right)\end{array}$ & $\begin{array}{c}20.88 \pm 3.46 \\
(16-29)\end{array}$ & $\begin{array}{c}22.65 \pm 3.45 \\
(16-32)\end{array}$ & 4.0603 & $<0.001 *$ \\
\hline Waist : Hip ratio & $\begin{array}{c}0.97 \pm 0.06 \\
(1-1)\end{array}$ & $\begin{array}{c}1.01 \pm 0.09 \\
(0-1)\end{array}$ & 4.2303 & $<0.001^{*}$ \\
\hline
\end{tabular}

Values: Mean $\pm \mathrm{SD}$ (figures in the parenthesis indicate the range) 
Table 2: Physiological parameters of two groups of bus drivers

\begin{tabular}{|c|c|c|c|c|}
\hline \multirow{2}{*}{ Parameter } & \multicolumn{2}{|c|}{ Bus drivers } & \multirow{2}{*}{ t value } & \multirow{2}{*}{$P$ value } \\
\hline & Group $1(n=140)$ & Group $2(n=114)$ & & \\
\hline $\begin{array}{c}\text { Experience } \\
\text { (years) }\end{array}$ & $\begin{array}{c}5.58 \pm 1.91 \\
(3-9)\end{array}$ & $\begin{array}{c}13.86 \pm 3.38 \\
(10-25)\end{array}$ & 24.5714 & $<0.001 *$ \\
\hline $\begin{array}{c}\text { Heart rate } \\
\left(\text { Beats } \min ^{-1}\right)\end{array}$ & $\begin{array}{c}76.76 \pm 4.70 \\
(64-86)\end{array}$ & $\begin{array}{c}78.42 \pm 5.06 \\
(64-88)\end{array}$ & 2.7049 & $=0.0073^{*}$ \\
\hline $\begin{array}{c}\text { SBP } \\
(\mathrm{mm} \text { of } \mathrm{Hg})\end{array}$ & $\begin{array}{c}122.71 \pm 3.65 \\
(116-134)\end{array}$ & $\begin{array}{c}125.82 \pm 6.71 \\
(116-142)\end{array}$ & 4.6978 & $<0.001^{*}$ \\
\hline $\begin{array}{c}\text { DBP } \\
(\mathrm{mm} \text { of } \mathrm{Hg})\end{array}$ & $\begin{array}{c}81.46 \pm 2.55 \\
(76-88)\end{array}$ & $\begin{array}{c}83.04 \pm 3.96 \\
(74-96)\end{array}$ & 3.8435 & $=0.0002 *$ \\
\hline
\end{tabular}

Values: Mean $\pm \mathrm{SD}$ (figures in the parenthesis indicate the range)

Table 3: Biochemical parameters of two groups of bus drivers

\begin{tabular}{|c|c|c|c|c|}
\hline \multirow[b]{2}{*}{ Parameter } & \multicolumn{2}{|c|}{ Bus drivers } & \multirow[b]{2}{*}{ t value } & \multirow[b]{2}{*}{$P$ value } \\
\hline & Group $1(n=140)$ & Group $2(n=114)$ & & \\
\hline $\begin{array}{l}\text { Hemoglobin } \\
\left(\mathrm{gmdl}^{-1}\right)\end{array}$ & $\begin{array}{c}15.39 \pm 1.31 \\
(12-20)\end{array}$ & $\begin{array}{c}15.08 \pm 1.38 \\
(12-20)\end{array}$ & 1.8313 & $=0.0682$ \\
\hline $\begin{array}{l}\text { Blood glucose } \\
\left(\mathrm{mgdl}^{-1}\right)\end{array}$ & $\begin{array}{c}91.92 \pm 14.31 \\
(68-197)\end{array}$ & $\begin{array}{c}94.50 \pm 20.36 \\
(68-238)\end{array}$ & 1.1831 & $=0.2379$ \\
\hline $\begin{array}{l}\text { SGPT } \\
\text { (IU/L) }\end{array}$ & $\begin{array}{c}30.87 \pm 21.44 \\
(9-120)\end{array}$ & $\begin{array}{c}64.40 \pm 45.42 \\
(18-187)\end{array}$ & 7.7419 & $<0.001^{*}$ \\
\hline $\begin{array}{l}\text { SGOT } \\
\text { (IU/L) }\end{array}$ & $\begin{array}{c}26.09 \pm 31.26 \\
(8-185)\end{array}$ & $\begin{array}{c}70.90 \pm 59.90 \\
(10-215)\end{array}$ & 7.6642 & $<0.001^{*}$ \\
\hline
\end{tabular}

Values: Mean $\underline{+S D}$ (figures in the parenthesis indicate the range)

Table 4: Demographic profile of two groups of bus drivers

\begin{tabular}{|c|c|c|c|}
\hline \multirow{2}{*}{\multicolumn{2}{|c|}{ Question }} & \multicolumn{2}{|c|}{ No. of response $(\%)$} \\
\hline & & Group $1(n=140)$ & Group $2(n=114)$ \\
\hline a) & \begin{tabular}{ll}
\multicolumn{2}{l}{ Marital status } \\
1) & Married \\
2) & Unmarried \\
3) & Widow \\
4) & Divorced \\
5) & Separated
\end{tabular} & $\begin{array}{c}102(72.9) \\
37(26.4) \\
0(0) \\
1(0.7) \\
0(0)\end{array}$ & $\begin{array}{c}105(92.1) \\
6(5.3) \\
0(0) \\
3(2.6) \\
0(0)\end{array}$ \\
\hline b) & $\begin{array}{l}\text { Educational level } \\
\text { 1) Illiterate } \\
\text { 2) Upto V } \\
\text { 3) Upto X } \\
\text { 4) Upto XII } \\
\text { 5) College }\end{array}$ & $\begin{array}{c}21(15.0) \\
78(55.7) \\
33(23.6) \\
8(5.7) \\
0(0)\end{array}$ & $\begin{array}{c}43(37.7) \\
51(44.7) \\
20(17.6) \\
0 \\
0\end{array}$ \\
\hline c) & $\begin{array}{l}\text { No. of family members } \\
\text { 1) } 1-3 \\
\text { 2) } \\
\text { 3) } \\
\text { 4) } \\
\text { 4) }\end{array}$ & $\begin{array}{c}37(26.4) \\
79(56.4) \\
21(15.0) \\
3(2.2)\end{array}$ & $\begin{array}{c}19(16.7) \\
57(50.0) \\
30(26.3) \\
8(7.0)\end{array}$ \\
\hline d) & $\begin{array}{l}\text { Income per month } \\
\text { 1) } 4,000-6,000 \\
\text { 2) } 6,000-8,000 \\
\text { 3) } 8,000-10,000 \\
4) \quad>10,000\end{array}$ & $\begin{array}{c}0(0.0) \\
73(52.1) \\
49(35.0) \\
18(12.9)\end{array}$ & $\begin{array}{c}2(1.8) \\
34(29.8) \\
54(47.4) \\
24(21.0)\end{array}$ \\
\hline e) & $\begin{array}{l}\text { Dietary practice } \\
\text { 1) Vegetarian } \\
\text { 2) Non-Vegetarian }\end{array}$ & $\begin{array}{c}3(2.1) \\
137(97.9)\end{array}$ & $\begin{array}{c}13(11.4) \\
101(88.6)\end{array}$ \\
\hline
\end{tabular}

Values: Number of response (Figure in the parenthesis indicate the percentage) 
Table 5: Personal habits of the two groups of bus drivers

\begin{tabular}{|c|c|c|}
\hline \multirow{2}{*}{ Type of addiction } & \multicolumn{2}{|c|}{ Number of Bus drivers (\%) } \\
\cline { 2 - 3 } & Group 1 (n=140) & Group 2 (n=114) \\
\hline Cigarette & $42(30.0)$ & $81(53.5)$ \\
\hline Bidi & $64(45.7)$ & $82(71.9)$ \\
\hline Chewing Tobacco & $87(62.1)$ & $49(43.8)$ \\
\hline Ghutka & $41(29.3)$ & $28(24.6)$ \\
\hline Ganja & $12(8.6)$ & $102(89.5)$ \\
\hline Alcohol & $92(65.7)$ & \\
\hline
\end{tabular}

Values: Number of response (Figure in the parenthesis indicate the percentage)

Table 6: Working environmental conditions as felt by the two groups of bus drivers

\begin{tabular}{|c|c|c|c|}
\hline \multirow{2}{*}{\multicolumn{2}{|c|}{ Working environment }} & \multicolumn{2}{|c|}{ Response (\%) } \\
\hline & & Group $1(n=140)$ & Group $2(n=114)$ \\
\hline \multirow{4}{*}{$\begin{array}{l}\text { a) } \\
\text { 1) } \\
\text { 2) } \\
\text { 3) } \\
\text { 4) }\end{array}$} & \multirow{4}{*}{$\begin{array}{l}\text { In summer } \\
\text { Hot } \\
\text { Humid } \\
\text { Noisy } \\
\text { Dusty }\end{array}$} & $125(89.2)$ & $103(90.3)$ \\
\hline & & $102(72.8)$ & $100(87.7)$ \\
\hline & & $41(29.2)$ & $38(33.3)$ \\
\hline & & $45(32.1)$ & $32(28.1)$ \\
\hline & \multirow{4}{*}{$\begin{array}{l}\text { In winter } \\
\text { Hot } \\
\text { Humid } \\
\text { Noisy } \\
\text { Dusty }\end{array}$} & $18(12.8)$ & $15(13.1)$ \\
\hline & & $11(7.8)$ & $08(7.01)$ \\
\hline & & $43(30.7)$ & $29(25.4)$ \\
\hline & & $75(53.6)$ & $56(49.1)$ \\
\hline
\end{tabular}

Values: Number of response (Figure in the parenthesis indicate the percentage)

Table 7: Rotated component matrix of eight variables of two groups of bus drivers

Rotated Component Matrix ${ }^{\mathrm{a}}$

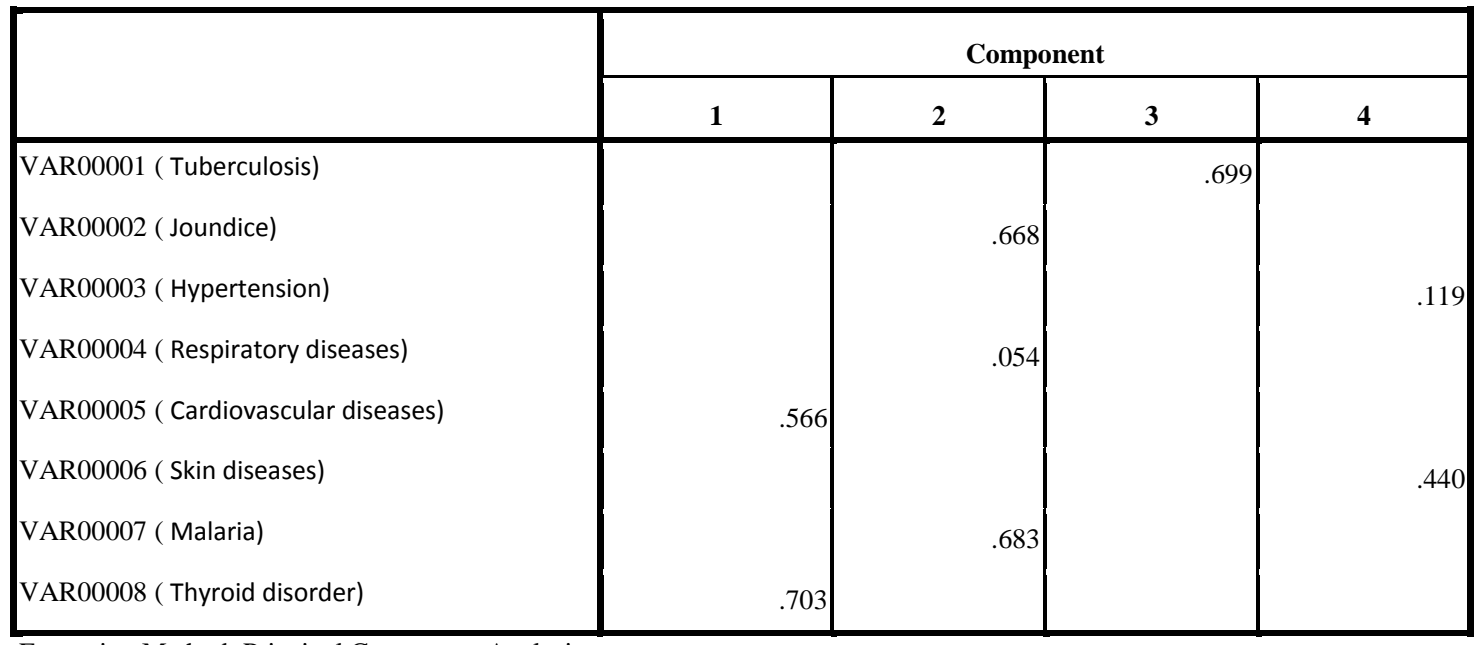

Extraction Method: Principal Component Analysis.

Rotation Method: Varimax with Kaiser Normalization.

a. Rotation converged in 9 iterations. 


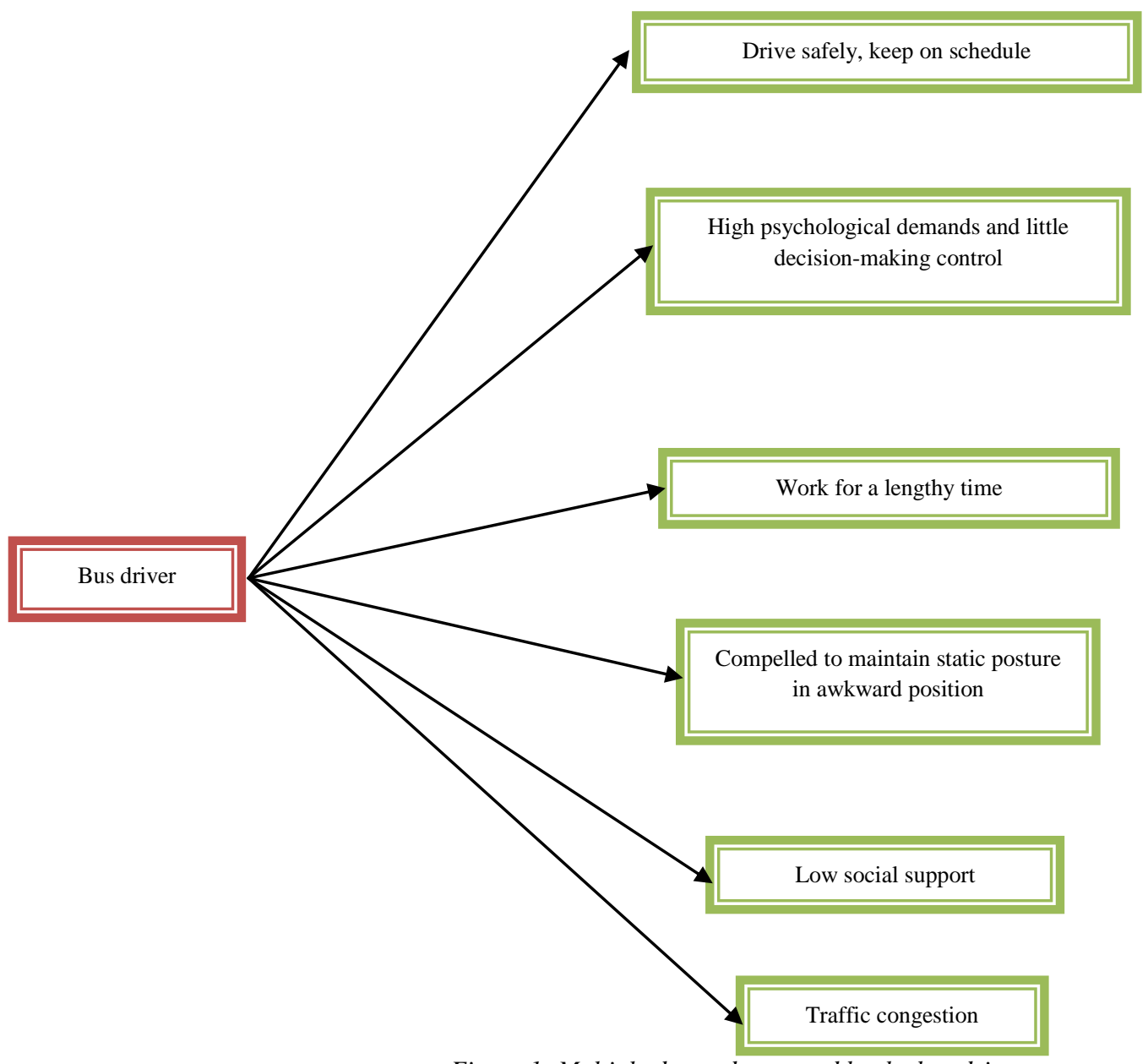

Figure 1: Multiple demands respond by the bus drivers

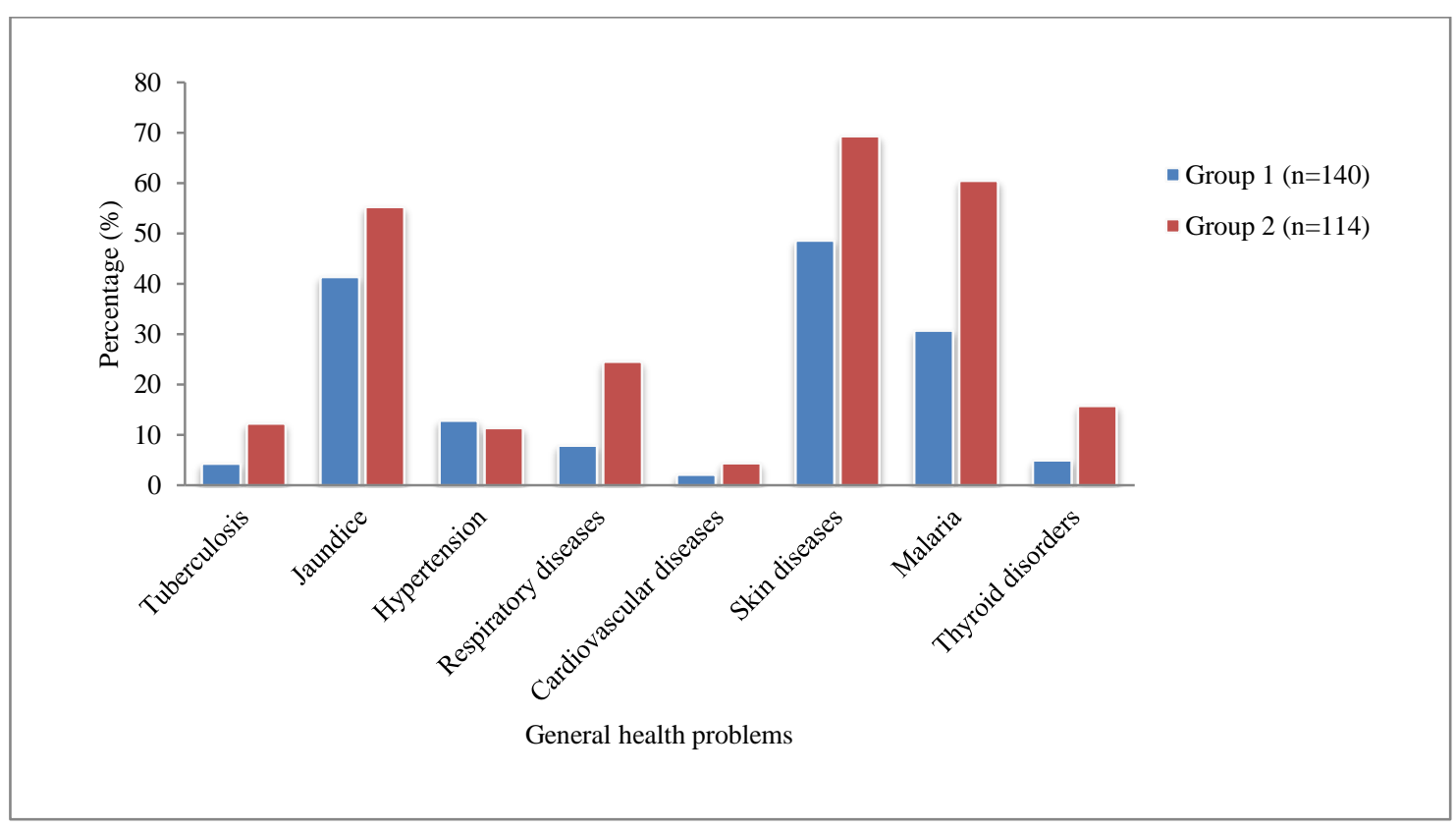

Figure 2: General health complaints of the two groups of bus drivers 
Rescaled Distance Cluster Combine

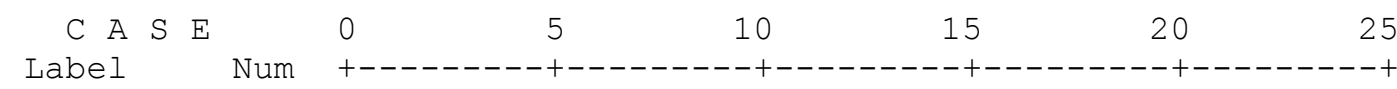

VAR00005

VAR00008

VAR00001

VAR00004

VAR00003

VAR0 0007

VAR0 0002

VAR00006

5
8
1
4
3
7
2
6

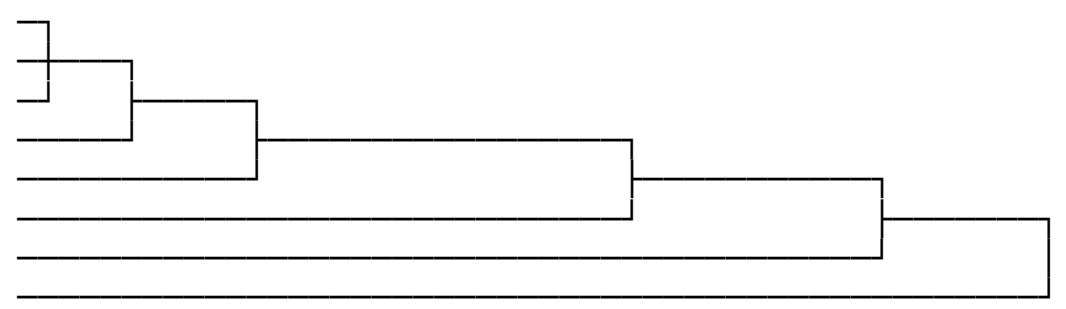

Variable 1 Tuberculosis, Variable 2 Joundice, Variable 3 Hypertension, Variable 4 Respiratory diseases, Variable 5 Cardiovascular diseases , Variable 6 Skin diseases, Variable 7 Malaria, Variable 8 Thyroid disorder

Figure 3: The hierarchical relationship on general health problems between two groups of bus driver using Dendrogram

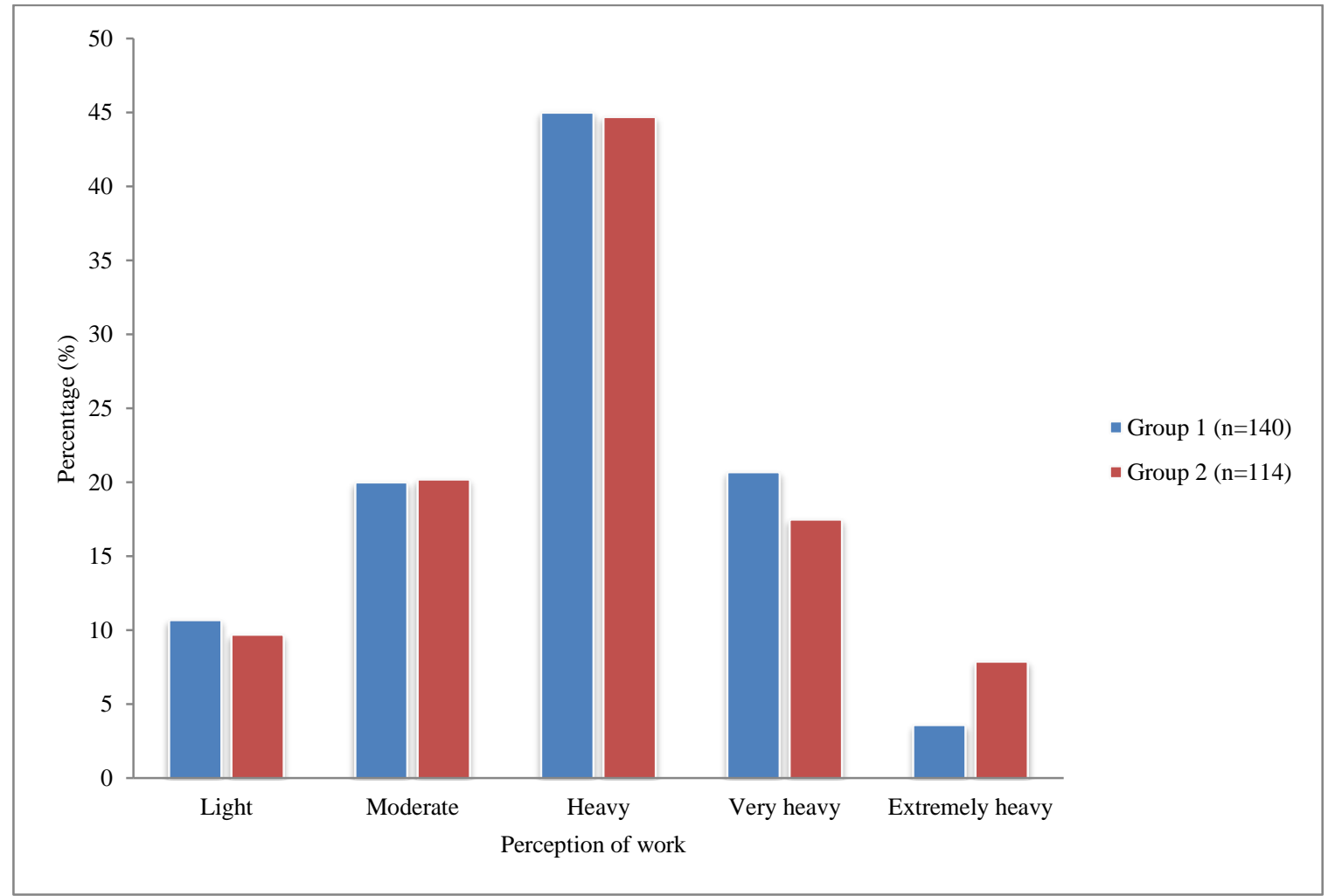

Figure 4: Perception about the job of the two groups of bus drivers 


\section{REFERENCES}

[1] M.A.J. Kompier, V. Dimartino, "Review of bus drivers' occupational stress and stress prevention”, Stress Medicine, Vol. 11, pp. 253-262, 1995.

[2] J.L.M. Tse, R. Flin, K. Mearns, "Bus driver well-being review: 50 years of research", Transportation Research Part F: Traffic Psychology and Behaviour, Vol. 9, pp. 89-114, 2006.

[3] M.A. Winkleby, D.R. Ragland, J.M. Fisher, S.L. Shyme, "Excess risk of sickness and disease in bus drivers: A review and synthesis of epidemiological studies", Int J Epidemiol, Vol. 17, pp. 255-262. 1988.

[4] S.R. Kartikeyan, B. Gurav, S.D. Joshi, W. Reshma, "Health and socio demographic profile of transport workers", Ind J Occ Environ Med, Vol.8, pp. 8-10, 2004.

[5] Z. Szubert, W. Sobala, "Health reasons for work disability among municipal transport drivers", Med Pr, Vol. 56, pp. 285-93, 2005.

[6] R.G. Villar, R.L. Shapiro, S. Busto, C. Riva-Posse, G. Verdejo, M.I. Farace, F. Rosetti, J.A. San Juan, C.M. Julia, J. Becher, S.E. Maslanka, D.L. Swerdlow, "Outbreak of type A botulism and development of a botulism surveillance and antitoxin release system in Argentina”, JAMA., Vol. 281, pp. 1334-1340, 1999.

[7] P.O. Bylund, U. Björnstig, T.J. Lasson, "Occupational road trauma and permanent medical impairment", Safety Science, Vol. 26, pp. 187-200, 1997.

[8] L. Evans, "Traffic Safety and the Driver. New York", Van Nostrand Reinhold, 1991.

[9] M.S. Dev, "Government interventions and social security for Rural Labour in Empowering Rural Labour in India", Radhakrishna and S.N. Sharma, (Eds), Institute for Human Development, New Delhi, 1998.

[10] S.P. Gupta, "Globalization, Economic reforms and Employment Strategy in India", Academic foundations, New Delhi, 2006.

[11] R.V. Agnihotram, "An overview of occupational health research in India”, Indian J Occup Environ Med, Vol. 9, pp.4$10,2005$.

[12] B. Ryan, C.M. Haslegrave, "Developing a verbal protocol method for collecting and analyzing reports of workers' thoughts during manual handling tasks", Appl Ergon, Vol. 38, pp. 805-819, 2007.

[13] C.A. Burtis, E.R. Ashwood, D.E. Bruns, "Tietz fundamentals of clinical chemistry. 6th ed. St. Louis", Saunders Elsevier; 2007. ISBN: 978-0-7216-3865-2.

[14] M.A. Sinclair, “Questionnaire design”, Appl Ergon, Vol. 6, pp. 73-80, 1975.

[15] D. Das, A. Das, "Statistics in Biology and Psychology, 4th edn", Academic publishers, Calcutta, 2004.

[16] WHO, "Waist Circumference and Waist-Hip Ratio: Report of a WHO Expert Consultation", 8-11 December 2008, World Health Organisation, Geneva. 2011.

[17] C.K. Pradhan, I. Chakraborty, S. Thakur, S. Mukherjee, "Physiological and Metabolic Status of Bus Drivers", In 'Ergonomics in Caring for People', In the Proceedings of the 2015 International Conference on Humanizing Work and Work Environment, India, pp. 161-168, 2018.

[18] S. Tiwari, J. Sikka, "Air Pollution Induced changes in foliar morphology of two tree species at Indore city", Int. J. Sci. Res. in Biological Sciences, Vol. 2, Issue. 4, PP. 15-19, 2015.

\section{AUTHORS PROFILE}

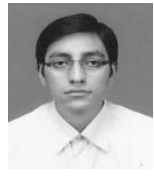

Mr. S. Mukherjee pursed B.Sc and M.Sc in Physiology from University of Calcutta in 2009 \& 2011. He is currently pursuing Ph.D in Physiology from University of Kalyani. After M.Sc he was working as a Research Assistant on a ICMR sponsored project at Regional Occupational Health Centre (Eastern) Block DP, Sector V, Salt Lake, Kolkata. He has 6 years of research experience. He has published 4 research papers in reputed international and national journals. He has also delivered lectures in international and national conferences. His main research work focuses on Ergonomics, Work Physiology, Occupational Health and intervention policy.

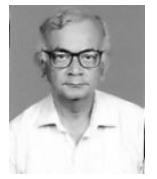

Dr. C. K Pradhan pursed B.Sc, M.Sc and Ph.D in Physiology from University of Calcutta in 1975, 1977 \& 1989. He is currently working as a Scientist 'E' \& Officer-in-Charge of Regional Occupational Health Centre (Eastern) Block DP, Sector V, Salt Lake, Kolkata. He has 39 years of research and teaching experience. He has published 39 research papers in reputed international and national journals and delivered lectures in conferences. His main research work focuses on Ergonomics, Work Physiology, Occupational Health and Product Design. He is a member of Indian Society of Ergonomics, Indian Association of Occupational Health, Indian Science Congress Association, Physiological Society of India, and Association of Physiologists and Pharmacologists of India. 


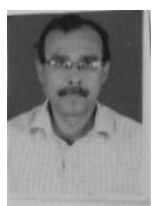

Dr. I. Chakraborty is working as Professor \& Head, Dept of Biochemistry ,College of Medicine \&Sagore Dutta Hospital,Kamarhati ,Kolkata:700058 for the last 3years. He served different Medical Colleges in West Bengal as a Professor \&Head since 2003. He is actively engaged in teaching of MBBS,M.Sc., M.D. students for the last 28 years . He also takes active part in conducting research in areas of occupational health, micronutrient deficiency disorders, Quality Control of laboratories ,determining Reference Interval of various biochemical parameters in Bengali Population. He has 19 publications in different international and 30 in national journals. He was a member of task force of ICMR "INCLAP" Project and Iodine

Deficiency Disorder Project. He is an examiner of MBBS,M.Sc,M.D. and PhD of various universities and Institutions.

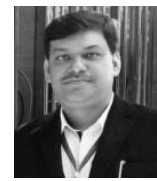

Dr. A. Saha is presently working as an Assistant Professor of Physiology at Sister Nibedita Govt. College, Alipore, W.B. He completed his Ph.D work in Physiology in 2014 from University of Kalyani. He has more than fourteen years of teaching experience in higher education and higher secondary level. He was a former head, Dept of Physiology, Kaliganj Govt. College. He was the best paper award winner in Science Congress in 2012. He has published more than twelve papers in reputed national and international journal. Dr. Saha acted as an Editor of Police Journal (2004-2005), Police Training College, Govt. of West Bengal. Now he is a member of different academic and administrative bodies.

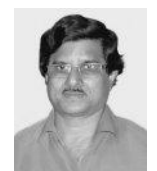

Mr. S Thakur, BSc. from Burdwan University in 1980. He is life member of Indian Society of Ergonomics. He is currently working as Sr. Technical Officer in Department of Ergonomics, Regional Occupational Health Centre (Eastern), Kolkata. He has 33 years experience in occupational health related work. He has published more than 20 research papers in reputed national and international journals. He has a patent (No.247859) on "Transportation Device".

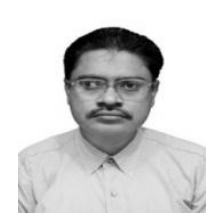

Dr. S. Sahu graduated from Presidency College, Calcutta. He has MSc. and PhD degree in Physiology with specialization in Ergonomics and Occupational Physiology from University of Calcutta. He is an Associate Professor and presently Head, Department of Physiology, University of Kalyani, West Bengal, India. He participated in several multinational collaborative studies on morningness orientation, mood disorders, eating habit and occupational heat exposure. His research work include evaluation of different occupational health problems including musculoskeletal disorders in different group of workers, its ergonomic evaluation, preventive measure, designing and sustainable remediation. He was conferred FABMS title from Association of Biomedical Scientist for his contribution in biomedical Sciences. His expertise includes analysis of posture in different conditions, design of work station and ergonomic evaluation of cognitive and motor skill. He has special interest in ergonomic evaluation capability and limitation of disabled person. He has published 94 full papers and seven PhD degrees have been awarded under his supervision. 